University of Nebraska - Lincoln

DigitalCommons@University of Nebraska - Lincoln

\title{
Systematics of gastrointestinal nematodes of domestic ruminants: advances between 1992 and 1995 and proposals for future research
}

J.R. Lichtenfels

E.P. Hoberg

D.S. Zarlenga

Follow this and additional works at: https://digitalcommons.unl.edu/usdaarsfacpub

This Article is brought to you for free and open access by the U.S. Department of Agriculture: Agricultural Research Service, Lincoln, Nebraska at DigitalCommons@University of Nebraska - Lincoln. It has been accepted for inclusion in Publications from USDA-ARS / UNL Faculty by an authorized administrator of DigitalCommons@University of Nebraska - Lincoln. 


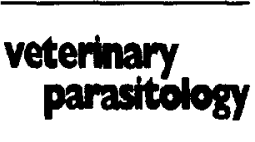

Veterinary Parasitology 72 (1997) 225-245

\title{
Systematics of gastrointestinal nematodes of domestic ruminants: advances between 1992 and 1995 and proposals for future research
}

\author{
J.R. Lichtenfels*, E.P. Hoberg, D.S. Zarlenga \\ Biosystematics and National Parasite Collection Unit, Agricultural Research Service, US \\ Department of Agriculture, Beltsville Agricultural Research Center, Beltsville, MD 20705-2350, \\ USA
}

\begin{abstract}
The systematics of trichostrongyloid nematodes of ruminants provides a foundation for diagnostics and responds to the need to identify eggs in feces, free-living larvae from pastures or fecal cultures and larval or adult nematodes collected from hosts. These needs are associated with diagnostic problems or research projects. Difficulties in identifying all developmental stages of trichostrongyloid nematodes of domestic ruminants still severely limit the effective diagnosis and control of these parasites. Phylogenetic hypotheses as the basis for predictive classifications have been developed only for the subfamilies of the Trichostrongylidae. This report briefly describes recent progress in the development of improved tools for identification, phylogenetic analyses and predictive classifications. It also describes future research needed on the identification and classification of trichostrongyloid nematode parasites of domestic ruminants. Nematodes included are species of the superfamily Trichostrongyloidea known to be important pathogens of domestic ruminants. The information summarized is presented by nematode developmental stage and by taxonomic groups. Eggs: While eggs of some trichostrongyloid nematode parasites of ruminants can be readily identified to their genus (Nematodirus), and some to species (e.g. Nernatodirus battus), most of the important pathogens (including the Ostertagiinae and Haemonchinae) cannot be identified morphologically or morphometrically even to family level. However, DNA technology has been developed for determining not only the presence of specific pathogens in eggs from fecal samples, but also for estimating the percentage of the total eggs that each pathogen comprises. This new method will make possible a rapid determination of which individual animals in a herd should be treated. Larvae: The most commonlyused method for identifying infective larvae is time-consuming (several weeks), unreliable
\end{abstract}

\footnotetext{
* Corresponding author.
} 
for estimating intensities of individual species as components of mixed populations and requires highly trained specialists. Available identification keys for larvae are not well illustrated and need to be augmented. Adults: Recent advances in the identification of adult trichostrongyloids and their systematics are organized by taxonomic group. Genera included are Ostertagia, Haemonchus, Cooperia, Trichostrongylus and Nematodirus. Recently, the first phylogenetic analysis of the Trichostrongylidae family established monophyly for the family. A similar analysis of the Molineidae is needed. Ostertagia: Several studies of polymorphism summarized the phenomenon and listed 19 polymorphic species in five genera. Two studies of DNA differences within and among polymorphic species of Ostertagiinae supported earlier hypotheses that the species pairs represent polymorphic species. A phylogenetic analysis of the Ostertagiinae and generic concepts are needed. Haemonchus: A key to three species of Haemonchus provides, for the first time, morphological characteristics for the microscopical identification to species of individual adult nematodes of either sex. The Food and Drug Administration is now requiring that results of drug trials include identification of Haemonchus to species. Cooperia: Studies using random amplified polymorphic DNA methods showed a high degree of variation within and among $C$. oncophora/C. sumabada, but supported a polymorphic relationship for the species pair. A phylogenetic analysis of the Cooperiinae is needed. Trichostrongylus: Restriction Fragment Length Polymorphisms (RFLPs) of genomic DNA of two strains of $T$. colubriformis indicated a high degree of intraand inter-strain DNA polymorphism. However, other studies demonstrated expected species level differences between $T$. colubriformis and T. vitrinus using Random Amplified Polymorphic DNA (RAPD) methods. Sequences of the second Internal Transcribed Spacer Region (ITS-2) ribosomal repeat showed sequence differences of $1.3-7.6 \%$ among five well-defined species of Trichostrongylus. This provides a standard for species level differences within the Trichostrongylidae. Nematodirus: The origin of $N$. battus in the British Isles is still a mystery. Recently, DNA studies have provided evidence that populations on both coasts of the United States originated from Canada. A phylogenetic study of Nematodirus is in progress. Modern systematic methods have not yet been applied to the development of classifications for all subfamilies and most genera of the Trichostrongyloidea. Additional factors complicating these problems are a lack of knowledge of the parasites of wild bovids and cervids, the international transport of wild and domestic hosts and environmental changes that may alter the parasite fauna in a modern farm setting. Published by Elsevier Science B.V.

Keywords: Domestic Ruminants-Nematoda; Systematics-Trichostrongylidae; Ostertagia-Systematics; Cooperia-Systematics; Haemonchus-Systematics; Trichostrongylus-Systematics; Nematodirus-Systematics; Mecistocirrus

\section{Introduction}

Veterinarians and parasitologists routinely determine the intensity of gastrointestinal nematode infections based on counts of eggs in feces. Unfortunately, the eggs of the most important pathogens cannot be identified even to genus level and existing identification keys to either first-stage or infective third-larval stages (which can be cultured from eggs) are out-dated, time-consuming and extremely difficult to use even for experienced, trained technicians. Clinical diagnosis of specific nematode pathogens can only be inferred from generic level determina- 
tions and known host-parasite associations. These constraints on the direct identification and assessment of intensity of infection in individual animals of a herd often require the introduction of sentinel, worm-free animals to the pasture for specific periods after which they are killed so that adult nematodes, which are much easier to identify, can be obtained from the digestive tract. This use of sentinel animals permits an indirect assessment of herd parasitism generally, but does not provide information on individual animals in the herd. In the future, direct determination of the identity and intensity of infection for specific pathogens in individual animals may become routine and will have significant advantages including the selective treatment of individual hosts with heavy infections of known pathogens. This should reduce the cost of controlling the parasite, lessen any environmental impact of the drug and greatly reduce the chances for development of drug resistance in the nematode populations.

Serological methods have also been evaluated for use in diagnosing abomasal nematode infections. However, reliable individual diagnosis cannot be made by serum pepsinogen and gastrin measurements (Berghen et al., 1993). In addition, antibody detection methods are available, but until recently, ELISA tests for antibodies have been unable to distinguish between Ostertagia and Cooperia infections. However, recently de Graaf et al. (1995) developed an ELISA that can distinguish between Ostertagia and Cooperia infections.

Researchers on nearly all aspects of trichostrongyloid nematodes have requirements to identify individual adult specimens (and sometimes free-living and/or parasitic larvae). It is clear that the success of clinical control efforts and research to reduce losses to these nematode pathogens requires, firstly, that the pathogen be identified. Improved capabilities for identifying and classifying trichostrongyloid nematode parasites are also essential for understanding the epidemiology of the diseases they cause and for designing effective control programs. This report briefly describes recent progress in the development of improved identification aids and predictive classifications. It also indicates where additional research is needed on the identification and classification of trichostrongyloid nematode parasites of domestic ruminants.

Nematodes included are species of the superfamily Trichostrongyloidea known to be important pathogens of domestic ruminants. The information summarized is presented by nematode developmental stage and by taxonomic groups where appropriate.

\section{Advances: 1992-1995 and future research needs}

\subsection{Eggs}

While the eggs of some trichostrongyloid nematode parasites of ruminants can be readily identified to genus (Nematodirus) and some to species (e.g. Nematodirus battus), most of the important pathogens (including species of the Ostertagiinae and Haemonchiinae) cannot be morphologically or morphometrically identified 
even to family level despite imaging studies by Georgi and McCulloch (1989) and detailed microscopical studies of earlier workers (e.g. Shorb, 1939).

Significant progress toward the development of methods utilizing DNA-probes for identifying eggs in feces has been reported by Christensen et al. (1994a), Campbell et al. (1995) and Zarlenga (unpublished data, 1997). Christensen et al. (1994a) developed genus-specific DNA probes for eggs of Ostertagia, Haemonchus, Cooperia and Oesophagostomum of cattle. This method detected as few as 25 eggs and represented the first successful DNA probe for determining the presence of eggs of specific pathogens in cattle feces. Parenthetically, working with four species of Strongylus of horses, Campbell et al. (1995) demonstrated that DNA from a single egg could be amplified and sequenced to identify and classify species within a strongyloid genus. More recently, an exciting breakthrough in the laboratory of Zarlenga (unpublished data, 1997) has provided the technology for determining not only the presence of specific pathogens (eggs) in a sample of cattle feces, but also for estimating the percentage of the eggs that the most pathogenic form ( $O$. ostertagi) comprises. This method is based upon competitive PCR between dissimilar-sized internal transcribed ribosomal DNA repeat sequence among the common bovine gastrointestinal nematodes. Since the mixture of different genomic DNAs compete equally for the $\mathrm{PCR}$ reaction ingredients, the relative amounts of each resultant DNA fragment can be quantitated following gel elecrophoresis and ethidium bromide staining. When this technology is developed for clinical use, it will make possible a rapid determination of which individual animals in a herd should be drug-treated.

\subsection{Larvae}

Methods have been used for identifying either first-stage or infective third-stage larvae of trichostrongyloid nematodes of ruminants. The most commonly-used method involves fecal cultures to obtain infective third-stage larvae which can be identified by microscopic comparative morphological studies. This method is timeconsuming (several weeks), unreliable for estimating intensities of individual species in mixed populations (Dobson et al., 1992) and requires highly trained specialists. Available identification keys for third-stage larvae are not well illustrated and need to be improved. A second, less commonly used method involves culturing and identifying first-stage larvae. This is a more rapid method because this stage of development is attained in days instead of weeks. Although a recently-improved key to first-stage larvae of strongylid nematodes of cattle is available (Reinecke and Reinecke, 1994), this method still suffers from the same disadvantages described for third-stage larvae.

The identification of parasitic fourth-stage larvae of trichostrongyloid nematodes of ruminants is of practical importance in determining whether inhibition is occurring in nematode populations and in drug efficacy studies. The presence of inhibition affects decisions regarding the design of treatment programs. Descriptions of fourth-stage larvae of most species of trichostrongyloids of cattle are simple line drawings scattered in the literature (Douvres, 1957) and are not readily 
available. A key to fourth-stage larvae of trichostrongyloid nematodes of domestic sheep was developed by Thomas and Probert (1993), and this is a useful addition to our diagnostic aids. However, modern photomicrographs of diagnostic features are needed to illustrate a key to genera in cattle and sheep. A comparative morphology study of fourth-stage larvae should also provide information useful in a phylogenetic analysis of trichostrongyloid nematodes.

\subsection{Adults}

Recent advances in our knowledge of the identification of adult trichostrongyloids and their systematics are organized by taxonomic group. Groups included are the most important trichostrongyloid nematode pathogens of domestic ruminants: Ostertagiinae, Haemonchinae, Cooperinae, Trichostrongylinae and Nematodirinae. The first four of these five subfamilies belong in the family Trichostrongylidae. The Nematodirinae is a member of the family Molineidae.

Durette-Desset and Chabaud (1993) proposed elevating the superfamily Trichostrongyloidea to suborder level and recognizing three superfamilies within the new suborder: Trichostrongyloidea, Molineoidea and Heligmosomoidea. Unfortunately, they provided no basis, extending from comparative analyses to support elevation of these taxa to higher rank. We prefer to retain the uniform system proposed in the CIH Keys to Nematode Parasites of Vertebrates.

\subsection{Trichostrongylidae}

The first phylogenetic analysis of the family Trichostrongylidae established monophyly for the family and postulated new relationships among the six subfamilies based on comparative morphological analyses of 22 characters (Hoberg and Lichtenfels, 1994). Two major groups were postulated: the Cooperiinae clade (Cooperiinae and Libyostrongylinae + Trichostrongylinae), defined by a 1-3-1 bursal formula and reduced buccal capsule and the Graphidiinae clade (Graphidiinae and Haemonchinae + Ostertagiinae) defined by a reduced cephalic vesicle and thorn-like cervical papillae. Unpublished analyses of DNA sequence data among members of the Trichostrongylidae support the relationships derived from the morphologically-based phylogenetic tree (Newton et al., Personal Communication). Two economically important subfamilies, the Ostertagiinae and Haemonchinae are considered to have shared a putative common ancestor 23-28 million years ago (Hoberg and Lichtenfels, 1994). Diversification of these groups involved a high degree of cospeciation with the Bovidae and Cervidae. Additionally, the intestine was postulated as the ancestral habitat for the Trichostrongylidae.

\subsection{Ostertaginae}

The species of most interest are Ostertagia ostertagi of cattle and Teladorsagia circumcincta of sheep. Species normally parasitic in wildlife, but known to infect cattle include $O$. leptospicularis, $O$. bisonis, Marshallagia marshalli and numerous 
other species worldwide. The systematics of nematodes that cause Ostertagiosis in domestic and wild ruminants in North America, including a key to species, was reviewed 4 years ago for this group (Lichtenfels and Hoberg, 1993). More recently, several studies were published on polymorphism, or the species pairs phenomenon, that is common within some genera of the Ostertaginae. Drózdz (1995) summarized the phenomenon within the subfamily, listing 19 polymorphic species in five genera. However, his list included only species he studied, so it is incomplete. He concluded that the presence or absence of polymorphism is a generic character and that each polymorphic genus has a characteristic type of minor morph. A different aspect of polymorphism was studied by Suarez et al. (1995), who subjected $T$. circumcincta $/ T$. trifurcata to environmental differences and observed minor changes in the frequency of the $T$. trifurcata morph. Gasnier et al. (1993) studied five allozymes of three species pairs $(O$. ostertagi/O. lyrata; $O$. leptospicularis $/ O$. kolchida; and $T$. circumcincta $/ T$. trifurcata) and concluded that each pair was a single species. Two studies of DNA differences within and among polymorphic species of Ostertagiinae, by Humbert and Cabaret (1995) using Random Amplified Polymorphic DNA (RAPD) methods and Zarlenga (unpublished data, 1997), who sequenced the first Internal Transcribed Spacer Region (ITS-1) ribosomal DNA (rDNA) and mitochrondrial DNA (mtDNA), supported earlier hypotheses by numerous researchers that each species pair, in fact, represents a single dimorphic or polymorphic species. In a study of intraspecies variation, Blouin et al. (1995) studying sequence data of mtDNA of $O$. ostertagi from cattle, $T$. circumcincta from sheep and Mazamastrongylus odocoilei from white-tailed deer, found high, withinspecies diversities (average of 0.019-0.027 substitutions per site) between individuals from a population and very small net diversities between populations (averaging $0.0004-0.0008$ per site). Thus, almost all of the total genetic diversity (96-99\%) was distributed within populations. They proposed that the large, within-species population diversities, also found in $H$. contortus and $H$. placei, result from large population sizes and perhaps an accelerated rate of nucleotide substitution. They proposed further that the observed high, within-species population diversity and the apparent high gene flow among populations would favor the spread of resistance alleles for anthelmintics.

Instability in generic to species-level systematics and taxonomy continues tohinder progress on research with the Ostertaginae. This has emanated from two sources: (1) inadequate recognition of the distribution of polymorphism; and (2) lack of a phylogenetic concept for genera and species. In this regard, Drózdz (1995) presented the most recent synopsis of the subfamily. He recognized nine genera as valid and listed possible synonymies based on the concept of polymorphism. Among valid genera, Ostertagia, Teladorsagia, Orloffia, Marshallagia and Spiculopteragia were considered to exhibit polymorphism, whereas Camelostrongylus, Mazamastrongylus, Sawaria and Longistrongylus were characterized by monomorphic species. However, a phylogenetic analysis of the Ostertagiinae is needed and a series of studies by Hoberg (1996), Hoberg and Lichtenfels (1992), Hoberg and Lichtenfels (1994), Hoberg et al. (1993a-c) and Lichtenfels et al. (1993), Lichtenfels et al. (1996) have been conducted in support of this goal. 
Recent studies among the Ostertagiinae, have continued to identify the role of translocation of hosts and introduction of parasites as factors determining the continental and international distribution of species in such genera as Spiculopteragia and Ostertagia (Rickard et al., 1993; Van Baren et al., 1996). This further emphasizes the critical importance of systematics and taxonomy in the identification of potentially pathogenic species of parasites.

\subsection{Haemonchinae}

The Food and Drug Administration is now requiring that results of drug trials include identification of Haemonchus to species. When adult specimens are available, the most efficient method is to look for the paired sub-ventral ridges in the region of the esophagus of $H$. placei (Lichtenfels et al., 1994). Lichtenfels et al. (1994) published a key to the three species of Haemonchus ( $H$. contortus, H. placei and $H$. similis) parasitizing domestic ruminants, that provided for the first time, morphological characteristics for the microscopical identification to species of individual adult nematodes of either sex. Haemonchus contortus and $H$, placei can be separated by the presence in the latter of four unique ridges, two sub-ventrally and two sub-dorsally in the region of the esophagus. Callaghan and Beh (1994b) developed a genus-specific DNA repeat from genomic DNA that differentiated Haemonchus spp. from $T$. colubriformis and $T$. circumcincta. Zarlenga et al. (1994a) reported differences in the external transcribed spacer of ribosomal DNA of three species of Haemonchus ( $H$. contortus, $H$. placei and $H$. similis) and developed diagnostic methods for differentiating the species. Christensen et al. (1994b) developed a DNA probe specific for $H$. placei which, in combination with a genus-specific probe (Christensen et al., 1994a), could be used to differentiate $H$. placei and $H$. contortus. Stevenson et al. (1995) sequenced the ITS-2 of $H$. contortus and $H$. placei and concluded that the results also supported the recognition of both species. Results of RAPD studies (Humbert and Cabaret, 1995) of three vulval morphotypes of $H$. contortus (lobed, knobbed and smooth) supported earlier conclusions that they are morphotypes of a single species. A study of intraspecific variation in mtDNA sequences of $H$. placei and $H$. contortus was conducted by Blouin et al. (1995) similar to that described above for Ostertagia. More recently, Zarlenga (unpublished data, 1997) found differences between $H$. contortus and $H$. place $i$ within ITS-1 rDNA and mtDNA sequences.

Another member of the Haemonchinae, Mecistocirnus digitatus, is receiving increasing attention in southern Mexico, Central America and South America due to its expanding prevalence in cattle (Robert S. Rew, Personal Communication). This is a large, red stomach-worm, 20-40 mm in length, with long (4-7 mm) filiform spicules and a vulva near the anus. It can be distinguished from Haemonchus spp. by the distinctive characters of the spicules $(400-500 \mu \mathrm{m}$ in Haemonchus) and the vulval position ( $80 \%$ of body length in Haemonchus).

\subsection{Cooperiinae}

Among the species of Cooperia parasitic in domestic ruminants little progress 
has been reported in their identification and classification since a key to species was published by Lichtenfels (1977). However, they are a well-defined group of species that can be identified on the basis of spicule and/or synlophe morphology. Using random amplified polymorphic DNA, Humbert and Cabaret (1995) found a high degree of variation within and among $C$. oncophora $/ C$. surnabada, but they concluded that their results supported a polymorphic relationship for the species pair as proposed earlier by Isenstein (1971). Recently, systematists have refined the concept of the Cooperiinae and have transferred genera to it from other subfamilies within the Trichostrongylidae (Hoberg et al., 1993b). A phylogenetic analysis of the Cooperiinae is needed.

\subsection{Trichostrongylinae}

There are five species of Trichostrongylus parasitic in domestic ruminants worldwide ( $T$. axei, $T$. colubriformis, $T$. longispicularis, $T$. vitrinus and $T$. capricola). Several additional species have been reported in domestic ruminants in various parts of the world, but are probably accidental parasites of domestic hosts (Levine, 1980). Host specificity is low and all five species have been reported from both cattle and sheep and a variety of other hosts including man. They are small, slender nematodes (2-6 mm in length) without prominent cervical papillae or a synlophe. Their small size and notch-like excretory pore are useful in recognizing them. Species can be identified by characteristics of spicules and the copulatory bursa (Ransom, 1911; Levine, 1980; Boomker and Veermaak, 1986), but a modern treatment of the systematics of the genus is lacking.

Considerable work has been done recently on DNA characteristics of species of Trichostrongylus. Callaghan and Beh (1994a) reported a DNA probe useful for separating $T$. colubriformis from $H$. contortus and $T$. circumcincta. Their probe cross-reacted with other (but not all) species of Trichostrongylus. Grant and Whitington (1994) analyzed genomic DNA of two strains of $T$. colubriformis with a library of short probes. RFLPs indicated a high degree of intra- and inter-strain DNA polymorphism. However, Humbert and Cabaret (1995) demonstrated expected species level differences between $T$. colubriformis and $T$. vitrinus using RAPD methods. In addition, Hoste et al. (1995) sequenced the second Internal Transcribed Spacer Region (ITS-2) of the ribosomal gene repeat and found consistent sequence differences of 1.3-7.6\% among five species of Trichostrongylus. This is consistent with species level differences for this DNA fragment of the ribosomal gene repeat.

\subsection{Libyostrongylinae}

Species of Libyostrongylus infect ostriches and are associated with significant morbidity and mortality (Barton and Seward, 1993). Two species, L. douglassii and $L$. dentatus are now known to occur in North America and can be distinguished by morphological characters of adult worms and by the eggs in feces (Hoberg et al., 1995). Both species were apparently introduced with their hosts from sub-Saharan 
Africa and the potential for transmission to other avian species is unknown (Hoberg et al., 1995).

\subsection{Graphidiinae}

The generic-level composition of the Graphidiinae remains unresolved (Gibbons and Khalil, 1982; Durette-Desset, 1983). Comparative morphological studies of artiodactyle parasites resulted in the transfer (Hoberg and Lichtenfels, 1992) of Parostertagia heterospiculum to the Cooperiinae and Hyostrongylus rubidus to the Ostertagiinae (Hoberg et al., 1993c). Further analyses of Graphidioides Cameron, 1923 from rodents and primates, Graphidium Railliet and Henry, 1909 from lagomorphs and Graphinema Guerrero and Rojas 1964 from South American camelids are required for elucidation of relationships within the Graphidiinae.

\subsection{Molineidae}

A phylogenetic analysis of the Molineidae is required, but has not yet been accomplished. Genera of this family that are of economic interest include Nematodirus in bovids and cervids, Nematodirella in domestic sheep and wild ruminants (Lichtenfels and Pilitt, 1983b) and Lamanema in South American camelids (Hoberg et al., 1989).

\subsection{Nematodirinae}

Species of Nematodirus parasitic in domestic ruminants include seven species (of the nearly 45 species in the genus) worldwide, including $N$. abnormalis, $N$. battus, $N$. davtiani, $N$. filicollis, $N$. helvetianus, $N$. oiratianus and $N$. spathiger. Lichtenfels and Pilitt (1983a) presented a key to six of the seven species, excluding $N$. battus which was redescribed by Hoberg et al. (1986) after it was discovered in North America. Zarlenga et al. (1994b) sequenced the small subunit rDNA of $N$. battus as a preliminary step in confirming the identity and source of North American populations of $N$. battus. Although the origin of $N$. battus in the British Isles is still a mystery, Hoberg and Nadler (unpublished data, 1997) have evidence from DNA studies that populations on both coasts of the United States originated from Canada. A phylogenetic study of the Nematodirus is in progress (Hoberg, E.P., personal communication).

\section{Discussion and conclusions}

We have argued herein that improved identification keys to all developmental stages of trichostrongyloid nematodes of ruminants, including improved illustration, are urgently needed. More progress has been made in the last 4 years in developing molecular methods for identifying eggs and developmental stages than in improving the morphological identification of these stages. We should direct more research efforts toward the comparative morphology of both free-living and 
parasitic developmental stages. The comparative morphology of fourth-stage larvae may be of great value in unraveling unanswered questions about inhibited larvae.

In the past decade considerable progress has been reported in solving species level problems such as the polymorphism (species pairs) in the Ostertagiinae and determining that Haemonchus of sheep and cattle are separate species. Also, new characters such as the synlophe have been described that make possible identification of individual specimens of either nematode sex. These advances have opened the door for current and future studies on the development of diagnostic probes and improved classifications at generic and higher levels.

However, there are still many problems to be overcome. Currently we have no generally accepted concept of the genera of the Ostertagiinae, the medium stomach worms of ruminants and available classifications are not based on phylogenetic relationships. No phylogenetic analyses have been completed for the subfamilies of the Trichostrongylidae or for other families of the Trichostrongyloidea. The next decade will be marked by these analyses which will require a global approach to such genera as Haemonchus, the Ostertagiinae and other members of the Trichostrongyloidea.

Systematics provides the foundation for addressing a range of questions dealing with host-parasite interactions, epidemiology and distribution. Systematics synthesizes the data for understanding the relationships of parasitic helminths. Phylogenetic hypotheses, such as that presented for the Trichostrongylidae and those currently being developed for the Ostertagiinae, Nematodirinae and other trichostrongyloids, are necessary to provide a context to address the origins and subsequent history of nematode faunas in ruminants (Hoberg and Lichtenfels, 1994). Knowledge of phylogenetic structure and organismal relationships are necessary for examination of historical host-associations and geographic ranges occupied by host-parasite assemblages. Phylogeny may provide a predictive framework for understanding the behavior of parasites introduced into new hosts, environments and geographic localities. It also provides a basis for elucidation of speciation processes and for evaluating the role of domestication of hosts in the evolution of economically important helminths.

Current knowledge about the role of host-translocation in the introduction of exotic helminths of ruminants raises several interesting questions. Introductions of parasites have contributed to the difficulty of developing hypotheses for historical biogeographic relationships of many trichostrongylids (Drózdz, 1967; Hoberg and Lichtenfels, 1994). We can provide a morphological basis for recognition of a number of species such as $T$. circumcincta, Marshallagia marshalli and others which occur in both wild and domestic hosts throughout the world (e.g. Lichtenfels and Hoberg, 1993). However, it is not clear whether or not such nominal taxa may represent groups of cryptic species which are morphologically indistinguishable.

If we consider the Nearctic, it is likely that an endemic fauna of characteristic trichostrongylid nematodes occurred in wild ruminants prior to the introduction of domesticated bovids from Europe. Introduction of ostertagiines and other nematodes could have resulted in: (1) displacement of an endemic fauna; (2) hybridization with the endemic fauna and introgression; or (3) coexistence of a wild and 
domesticated fauna. Thus, are ostertagiines reported as $T$. circumcincta and $M$. marshalli in historically isolated populations of wild bovids conspecific with populations found in domesticated hosts? In this regard, Lichtenfels and Pilitt (1989) found consistent differences in the synlophes of forms designated Ostertagia $\mathrm{sp}$. and Marshallagia sp. from Oreamnos americana (mountain goat) in contrast to specimens of $O$. occidentalis and $M$. marshalli from Ovis spp., Odocoileus (deer) and Ovibos moschatus (musk ox). Thus, morphological criteria suggest the existence of definable populations which could indeed represent assemblages of sibling species. Such an hypothesis is testable, based on the application of the appropriate molecular-level characters. The solution of this potentially perplexing relationship has a bearing on understanding the patterns, processes and mechanisms involved in the diversification of helminth faunas in both domesticated and wild ruminants in the Holarctic.

Phylogenetic systematics can be conducted with characters derived from comparative morphology or molecular-level analyses. These are not mutually exclusive forms of data, but should be complementary in their application. The utility of a particular kind of character should be dictated by the hypothesis which is being addressed. The development of molecular probes, carefully validated by morphological data, will revolutionize the way eggs and larvae of specific pathogens are identified. However, it will take many years of expensive research to provide sufficient numbers of genetic characters to equal the information content available in comparative morphology. Molecular data has usually supported analyses based on comparative morphology. Comparative morphology will continue to provide the foundation and the practical methods for pathogen identification and classification for many years in the future.

Studies of the genetics of nematodes are blossoming (Grant, 1994; Nadler, 1995; Lymbery, 1996) now that PCR methods permit molecular studies of individual specimens and new morphological characters have made it possible to identify individual specimens of both sexes. A discussion of the genetics of individual characters or population genetics are beyond the scope of this paper. In the future these areas will provide information of great value to systematists, especially for determining the systematic value of morphological characteristics.

Continued progress in the systematics of these economically important nematodes will require the collaboration of workers in comparative morphology and molecular genetics. Both areas must be supported in the few remaining centers for systematics in order for progress to continue through the next decade. Species are unique gene pools with distinct characteristics such as reservoir hosts, seasonal and environmental preferences, pathology syndrome, drug susceptibility and site of parasitism in the host. It is essential that we know which gene pools we are dealing with when designing control programs for these economically important nematodes.

\section{References}

Barton, N.J., Seward, D.A., 1993. Detection of Libyostrongylus douglassi in ostriches in Australia. Aust. Vet. J. 70, 31-32. 
Berghen, P., Hinderson, H., Vercruysse, J., Dorney, P., 1993. Evaluation of pepsinogen, gastrin and antibody response in diagnosing ostertagiosis. Vet. Parasitol. 46, 175.

Blouin, M.S., Yowell, C.A., Courtney, C.H., Dame, J.B., 1995. Host movement and the genetic structure of populations of parasitic nematodes. Genetics 141, 1007-1014.

Boomker, J., Veermaak, D., 1986. Trichostrongylus angistris n. sp. from the red duiker Cephalophus natalensis A. Smith, 1834 and a redescription of Trichostrongylus minor Monnig, 1932. Onderstepoort J. Vet. Res. 53, 217-223.

Callaghan, M.J., Beh, K.J., 1994a. A middle-repetitive DNA sequence element in the sheep parasitic nematode Trichostrongylus colubriformis. J. Parasitol. 109, 345-350.

Callaghan, M.J., Beh, K.J., 1994b. Characterization of a tandemly repetitive DNA sequence from Haemonchus contortus. Int. J. Parasitol. 24, 137-141.

Campbell, A.J.D., Gasser, R.B., Chilton, N.B., 1995. Differences in a ribosomal DNA sequence of Strongylus species allows identification of single eggs. Int. J. Parasitol. 25, 359-365.

Christensen, C.M., Zarlenga, D.S., Gasbarre, L.C., 1994a. Ostertagia, Haemonchus, Cooperia, and Oesophagostomum: construction and characterization of genus-specific DNA probes to differentiate important parasites of cattle. Vet. Parasitol. 78, 93-100.

Christensen, C.M., Zarlenga, D.S., Gasbarre, L.C., 1994b. Identification of a Haemonchus placei-specific DNA probe. J. Helminthol. Soc. Wash. 6, 249-252.

Dobson, R.J., Barnes, E.H., Birclijin, S.D., Gill, J.H., 1992. The survival of Ostertagia circumcincta and Trichostrongylus colubriformis in faecal cultures as a source of bias in apportioning egg counts to worm species. Int. J. Parasitol. 22, 1005-1008.

Douvres, F.W., 1957. Keys to the identification and differentiation of the immature parasitic stages of gastrointestinal nematodes of cattle. Am. J. Vet. Res. 18, 81-85.

Drózdz, J., 1967. Studies on the helminths and helminthiases in Cervidae III: historical formation of the helminthofauna in Cervidae. Acta Parasitol. Pol. 14, 287-300.

Drózdz, J., 1995. Polymorphism in the Ostertagiinae Lopez-Neyra, 1947 and comments on the systematics of these nematodes. Syst. Parasitol. 32, 91-99.

Durette-Desset, M.C., 1983. Keys to the genera of the superfamily Trichostrongyloidea. No. 10. In: Anderson, R.C., Chabaud, A.G. (Eds.), CIH Keys to the Nematode Parasites of Vertebrates. Commonwealth Agricultural Bureaux, Farnham Royal, England, pp. 1-86.

Durette-Desset, M.C., Chabaud, A.G., 1993. Nomenclature des Strongylida au-dessus du groupe-famille. Ann. Parasitol. Hum. Comp. 68, 111-112.

Gasnier, N., Cabaret, J., Suarez, V., 1993. Species and morphs in the Ostertaginae: an allozyme study of seven species. Int. J. Parasitol. 23, 765-770.

Georgi, J.R., McCulloch, C.E., 1989. Diagnostic morphometry: identification of helminth eggs by discriminant analysis of morphometric data. J. Helminthol. Soc. Wash. 56, 44-57.

Gibbons, L.M., Khalil, L.F., 1982. A key for the identification of genera of the nematode family Trichostrongyloidea Leiper, 1912. J. Helminthol. 56, 185-233.

Grant, W.N., 1994. Genetic variation in parasitic nematodes and its implications. Int. J. Parasitol. 24, $821-830$.

Grant, W.N., Whitington, G.E., 1994. Extensive DNA polymorphism within and between two strains of Trichostrongylus colubriformis. Int. J. Parasitol. 24, 719-725.

de Graaf, D.C., Berghen, P., Hilderson, H., De Cock, H., Vercryusse, J., 1995. Identification and purification of Cooperia oncophora-specific antigens to improve serological diagnosis. Int. J. Parasitol. $23,141-144$.

Hoberg, E.P., 1996. Emended description of Mazamastrongylus peruvianus (Nematoda: Trichostrongyloidea), with comments on the relationships of the genera Mazamastrongylus and Spiculopteragia. J. Parasitol. (in press).

Hoberg, E.P., Fruetel, M., Rickard, L.G., 1989. Synlophe of Nematodinus odocoilei (Trichostrongyloidea) from deer and caribou in North America with comments on the evolution of Nematodirus spp. among the Cervidae (Artiodactyla). Can. J. Zool. 67, 1489-1494.

Hoberg, E.P., Lichtenfels, J.R., 1992. Morphology of the synlophe and genital cone of Parostertagia heterospiculum (Trichostrongyloidea), with comments on the subfamilial placement of the genus. Syst. Parasitol. 22, 1-16. 
Hoberg, E.P., Lichtenfels, J.R., 1994. Phylogenetic systematic analysis of the Trichostrongylidae (Nematoda), with an initial assessment of coevolution and biogeography. J. Parasitol. 80, 976-996.

Hoberg, E.P., Lichtenfels, J.R., Pilitt, P.A., 1993a. Comparative morphology of Ostertagia mossi and Ostertagia dikmansi (Trichostrongyloidea) from Odocoileus virginianus, with comments on other Ostertagiinae from the Cervidae. Syst. Parasitol. 24, 111-127.

Hoberg, E.P., Lichtenfels, J.R., Pilitt, P.A., 1993b. Synlophe of Cooperia neitzi (Trichostrongyloidea: Cooperiinae), with comments on vulval inflations and hypertrophy of cuticular ridges among the trichostrongylids. J. Helminthol. Soc. Wash. 60, 152-161.

Hoberg, E.P., Lichtenfels, J.R., Pilitt, P.A., 1993c. Affiliation of Hyostrongylus rubidus (Nematoda: Trichostrongyloidea), with the Ostertagiinae and evaluation of the synlophe and other structural characters. J. Helminthol. Soc. Wash. 60, 219-233.

Hoberg, E.P., Lloyd, S., Omar, H., 1995. Libyostrongylus dentatus n. sp. (Nematoda: Trichostrongyloidea) from ostriches in North America, with comments on the genera Libyostrongylus and Paralibyostrongylus. J. Parasitol. 81, 85-93.

Hoberg, E.P., Zimmerman, G.L., Lichtenfels, J.R., 1986. First report of Nematodirus battus (Nematoda: Trichostrongyloidea) in North America: redescription and comparison to other species. J. Helminthol. Soc. Wash. 53, 80-88.

Hoste, H., Chilton, N.B., Gasser, R.B., Beveridge, I., 1995. Differences in the second internal transcribed spacer (ribosomal DNA) between five species of Trichostrongylus (Nematoda: Trichostrongyloidea). Int. J. Parasitol. 25, 75-80.

Humbert, J.F., Cabaret, J., 1995. Use of random amplified polymorphic DNA for identification of ruminant trichostrongylid nematodes. Parasitol. Res. 81, 1-5.

Isenstein, R.S., 1971. The polymorphic relationship of Cooperia oncophora (Railliet, 1898) Ransom, 1907, to Cooperia sumabada Antipin, 1931 (Nematoda: Trichostrongyloidea). J. Parasitol. 57, 316-319.

Levine, N.D., 1980. Nematode Parasites of Domestic Animals and of Man, 2nd ed. Burgess Publ., Minneapolis, MN, p. 477.

Lichtenfels, J.R., 1977. Differences in cuticular ridges among Cooperia spp. of North American ruminants, with an illustrated key to species. Proc. Helminthol. Soc. Wash. 44, 111-119.

Lichtenfels, J.R., Pilitt, P.A., 1983a. Cuticular ridge patterns of Nematodirus (Nematoda: Trichostrongyloidea) of North American ruminants, with a key to species. Syst. Parasitol. 5, 271-285.

Lichtenfels, J.R., Pilitt, P.A., 1983b. Cuticular ridge patterns of Nematodirella (Nematoda: Trichostrongyloidea) parasitic in domestic ruminants of North America, with a key to species. Proc. Helminthol. Soc. Wash. 50, 261-274.

Lichtenfels, J.R., Hoberg, E.P., 1993. The systematics of nematodes that cause ostertagiasis in domestic and wild ruminants in North America; an update and a key to species. Vet. Parasitol. 46, 33-53.

Lichtenfels, J.R., Hoberg, E.P., Pilitt, P.A., Belem, A.M.G., 1993. A comparison of cuticular ridge patterns and other morphological characters of Mazamastrongylus odocoilei and Mazamastrongylus pursglovei (Nematoda: Trichostrongyloidea) from white-tailed deer Odocoileus virginianus. Syst. Parasitol. 24, 1-15.

Lichtenfels, J.R., Pilitt, P.A., 1989. Cuticular ridge patterns of Marshallagia marshalli and Ostertagia occidentalis (Nematoda: Trichostrongyloidea) parasitic in ruminants of North America. Proc. Helminthol. Soc. Wash. 56, 173-182.

Lichtenfeis, J.R., Pilitt, P.A., Hoberg, E.P., 1994. New morphological characters for identifying individual specimens of Haemonchus spp. (Nematoda: Trichostrongyloidea) and a key to species in ruminants of North America. J. Parasitol. 80, 107-119.

Lichtenfels, J.R., Hoberg, E.P., Pilitt, P.A., Craig, T.M., 1996. The synlophe and other structural characteristics of Sarwaria bubalis (Nematoda: Trichostrongyloidea) from cattle in Guyana. J. Parasitol. 82, 146-164.

Lymbery, A.J., 1996. Finding genetic markers for complex phenotypic traits in parasites. Int. J. Parasitol. 26, 7-17.

Nadler, S.A., 1995. Microevolution and the genetic structure of parasite populations. J. Parasitol. 81 , 395-403, 
Ransom, B.H., 1911. The nematodes parasitic in the alimentary canal of cattle, sheep and other ruminants. Bull. Bur. Anm. Ind. US Department of Agriculture No. 127, pp. 1-132.

Reinecke, R.K., Reinecke, N.D., 1994. Identification of first stage larvae $L_{1}$ of bovine nematodes. Pesqui. Vet. Braz. 14, 1-4.

Rickard, L.G., Hoberg, E.P., Allen, N.M., Zimmerman, G.L., Craig, T.M., 1993. Spiculopteragia spiculoptera and S. asymmetrica (Nematoda: Trichostrongyloidea) from red deer (Cervus elaphus) in Texas. J. Wildl. Dis. 29, 512-515.

Shorb, D.A., 1939. Differentiation of eggs of various genera of nematodes parasitic in domestic ruminants in the United States. Technical Bulletin No. 694. U.S.D.A. Washington, DC.

Stevenson, L.A., Chilton, N.E., Gasser, R.B., 1995. Differentiation of Haemonchus placei from $H$. contortus (Nematoda: Trichostrongylidae) by the ribosomal DNA second internal transcribed spacer. Int. J. Parasitol. 25, 483-488.

Suarez, V.H., Cabaret, J., Gruner, L., 1995. Morphological polymorphism in the nematode Teladorsagia circumcincta in relation to age of larvae, infection mode and lamb characteristics in experimental conditions. Int. J. Parasitol. 25, 1173-1177.

Thomas, D.R., Probert, A.J., 1993. A key to the identification of arrested gastrointestinal nematode larvae of sheep in Britain. Vet. Parasitol. 47, 77-80.

Van Baren, D., Hoberg, E.P., Botzler, R.G., 1996. Abomasal parasites in tule elk (Cervus elaphus nannodes) from Grizzly Island, California. J. Helminthol. Soc. Wash. (in press).

Zarlenga, D.S., Stringfellow, F., Nobary, M., Lichtenfels, J.R., 1994a. Cloning and characterization of ribosomal RNA genes from three species of Haemonchus (Nematoda: Trichostrongyloidea) and identification of PCR primers for rapid differentiation. Exp. Parasitol. 78, 28-36.

Zarlenga, D.S., Lichtenfels, J.R., Stringfellow, F., 1994b. Cloning and sequence analysis of the small subunit ribosomal RNA gene from Nematodirus battus. J. Parasitol. 80, 342-344.

\section{Discussion: Systematics of gastrointestinal nematodes of domestic ruminants: advances 1992-1995 and proposals for future research (Lichtenfels)}

(Conder - USA) We have observed differences between Nematodirus and other trichostrongylid nematodes. Is Nematodirus in a different group or family?

(Lichtenfels - USA) Eric Hoberg is working on Nematodirus. Would you respond to that question, Eric?

(Hoberg - USA) The Trichostrongyloidea is defined by a synapamorphe of the synlophe, that is, the presence of cuticular ridges; therefore, Nematodirus is correctly placed within the Trichostrongyloidea. When you get within the superfamily you have a number of families that are recognized. Nematodinus is clearly not a trichostrongylid because trichostrongylids are characterized by a number of other morphological attributes which Nematodinus does not have. The problem that Ralph (Lichtenfels) pointed out earlier about the Moleniidae (to which Nematodirus belongs) is that we don't have a classification or we don't understand relationships within the family. The moleniids may in fact not be a monophlyletic group, so where Nematodirus falls within the Trichostrongyloidea is not entirely clear at the moment. We can only say that it is not a trichostrongylid; we can do that based on a suite of very well-defined morphological characters. If you look at some of the other moleniids, Nematodirus does share characters with other moleniids. The problem is defining whether those characters are what we would 
call evolutionarily derived characters or primitive characters. We base relationships only on shared, derived characters in phylogenetic analysis and systematics. So, if we are only looking at primitive characters, this tells us nothing about relationship. Thus, at this point in time, without a phylogenetic analysis of the moleniids or a phylogenetic analysis of the families within the Trichostrongyloidea, we can't really say exactly where Nematodirus should be placed other than the fact that we know it is a trichostrongyloid based on the presence of the synlophe.

(Conder - USA) There clearly is a differential susceptibility for some drug classes, at least, but we run into problems trying to group things and to make generalizations. Nematodirus doesn't seem to fit any of those generalizations. My question gets really to what Eric said, is this an example where morphological characterization is not consistent with molecular characters?

(Lichtenfels - USA) It's more a case where morphological analysis hasn't been done adequately yet.

(Coles - UK) Could I ask you about tests for individual animals. In order for them to be realistic they have got to be very, very cheap. Do you ever see that coming about?

(Lichtenfels - USA) Maybe we ought to take a look at Dan Zarlenga's recent results and then we can discuss that. I realize the cost is going to be a problem and it may be a while in development before this is ever realized. But, this has been a goal that we've had for a long time, to be able to not only identify what's there for individual animals, but what the intensity is in a cheap inexpensive test. I'm really excited about Dan's recent progress. Dan, please show us what you've been able to do so far.

(Zarlenga - USA) I know that people cringe when they hear the concept PCR. I'm sure they react now when they think of its application toward diagnosis much the way people reacted 20 or 25 years ago when ELISA was developed. But we are in that age where diagnosis must jump to a higher level and PCR is clearly that level. I would just like to review briefly the area we're looking at in the genome of these parasites, namely the ribosomal RNA gene, specifically the associated ITR1 or ITS1. We developed PCR primers which span that region. We were doing this study originally for phylogenetics and wanted to sequence that region, but when we developed PCR primers, we amplified a fragment that was substantially different in Ostertagia ostertagi and Ostertagia lyrata from other nematodes of cattle. We also looked at Cooperia, Oesophagostomum, Nematodirus and Haemonchus contortus. All of these have a different band from the one characteristic for Ostertagia in this range. This led us to tentatively design PCR primers such that if there's a mixed population of parasites, one should presumably get both PCR bands from a mixed population of parasites. The advantage to this technique is that not only do you get these two bands (the top band being indicative of Ostertagia and the lower band 
essentially being indicative of all of the other types of Trichostrongylids that infect cattle) but because of the region that we're amplifying and the consistency that this region exists in all these parasites, you can actually quantitate the amount of Ostertagia eggs that are represented in your egg population. One method would be just by scanning those two lanes for band intensity. We have developed another method which does not require computer generated data. We synthesized a molecule we call a 'competitor' that is derived from these two regions of the DNA. It was designed to bind the same DNA primers as the native DNA molecule, such that as you decrease the amount of competitor, you can compare the intensity of the top lane to the competitor as well as the intensity of the bottom lane to the competitor. Because the competitor molecule is of a known concentration and you can obtain ratios of Ostertagia eggs to the total. Keep in mind that we're only talking about the percentages that Ostertagia represents of the total population of eggs. However, since this is the primary pathogen in most of the infections, we should be able to determine, which animals have high egg counts and of these, which include the high populations of Ostertagia.

(Lichtenfels - USA) Dan's results are not published yet and obviously there's a way to go in development, but I think this is an exciting indication that in the future we will be able to have fairly automated procedures that would be done to identify individual animals that need to be treated. It's too early to say what the cost would be, but I agree with you that we've got to have inexpensive tests in order for it to be economically feasible.

(Gasbarre - USA) One of the questions that you perceive coming up with this is your ability to extract the same amount of DNA from the different genera or species of the parasites. That is, if you're going to use it to quantitate or have a ratio of Ostertagia versus Cooperia for instance, what kind of experience does Dan have or anybody else have that indicates using a set procedure for extraction that you get similar amounts of a material back from the different genera or the different species within a genus?

(Zarlenga - USA) It's a good question,but look at our alternatives right now. One of those alternatives is to set up larval cultures. By the time you purify the eggs, if there's any damage at all to those eggs you'll get incorrect counts. You may know what species are in there, but in terms of percentage you will not if there's some damage to the eggs. However, the DNA may remain intact. We're not talking about all of the DNA, but even if it's partially degraded, a technique like this will be able to give us a reasonable estimate of the relative species composition in that population. On the other hand, if there's any damage whatsoever to the egg or if for any reason the egg does not develop in culture or if you assay the culture at a time which is not optimal for the egg development of one of the species you can have results which are clearly not representative of the egg population in the fecal material. For right now, I don't have an answer as to whether or not you get equal 
amounts of DNA from equal amounts of eggs, I think that is something that needs to be addressed. However, given the similarities among these eggs and the inability to diagnose them, I find that the likelihood is small and that isolation will be a greater problem or a larger source of error than those present in currently used methods.

(Borgsteede - The Netherlands) I think most of us know that the number of eggs in the feces is not always a reflection of the worm population in the host. So, if you have a very accurate estimation of what is present in the feces, what is the advantage of such a test?

(Lichtenfels - USA) It would provide an automated system for identifying animals with high egg counts and identify those with high Ostertagia egg counts and it could be performed quickly and at low cost by relatively untrained personnel.

(Zarlenga - USA) I'm going to turn this over to Lou Gasbarre for a few minutes. Part of the problem is not so much what is in the animal, but what is available for transmission. Because it's the transmission issue that needs to be addressed and Lou has been working on variability among animals, he can probably tell you a little bit more about the variability in egg production that you get within a herd.

(Gasbarre - USA) I don't know if we need to go over that but I think what Dan said at this point is true. It depends if you're talking therapeutic or strategic treatment in wanting to know what the pasture seeding is and if you're looking at control by controlling transmission with a strategic drug treatment, this kind of thing could be important. But you're right, there's a lot of variability among animals in fecal egg counts. But, what else do we have right now without killing the animal and counting the number of worms that are there.

(Lichtenfels- USA) There is some new information on Mecistocirrus. Rob Rew called to my attention recently that Mecistocirrus was being reported in Central and South America and at unexpectedly high rates. It seems that Mecistocirrus is now the most common stomach worm in those areas and I think it's something that we need to be aware of. I can tell you that it resembles Haemonchus, it's certainly in the same subfamily as Haemonchus, grossly it looks very similar, the vulva is much closer to the anus, rather than at about $80 \%$ of body length like Haemonchus, the spicules of Mecistocirnus are a lot longer, so it shouldn't be that difficult to identify if you're aware that it might be there. This is an example of what I'm calling in this chart competitive displacement among nematode parasites of ruminants. Another example of this is Nematodinus battus in sheep in Norway. When $N$. battus was imported into Norway, it completely displaced the other Nematodirus species within a short time. More recently Haemonchus contortus replaced H. similis in Brazil. Competitive displacement is something that we need to be aware of. Don't expect that because you found a ratio of certain species over 
the years that it might not change. Have any of you seen Mecistocirrus in other places?

(Vercruysse - Belgium) We are looking for Mecistocirrus in the Phillippines; it's quite common, I would say about $100 \%$. But it is common also to find Haemonchus and we don't have the feeling that there is any kind of competition between the two species. One thing we see most common are quite low worm burdens. We did quite a few autopsies for Mecistocirrus and found an average of about 5200 worms.

(Lichtenfels - USA) Rob, is that different from what you found?

(Rew - USA) No, we've been running a series of trials in southern Mexico, Central America, the northern part of South America especiallyand into the northern part of Brazil. We've continued to see Mecistocirrus in all the abomasa over and over again. We're seeing from 5000 to 6000 up to 10000 per animal especially in Columbia and Venezuela and Central America.

(Lichtenfels - USA) Certainly we need to learn more about Mecistocirrus. Apparently there is only one species worldwide, but the last systematic analysis that I'm aware of was done in 1965 and published in the Journal of Parasitology.

(Vercruysse - Belgium) I'm still concerned with identification between Haemonchus contortus, $H$. placei and $H$. longistipes in Africa; how do you do it in a practical sense like in doing egg counts and what would you recommend to say to put a name on all of the species. I called them Haemonchus spp.

(Lichtenfels - USA) So far in the US we've only had to be concerned with three species, $H$. similus, $\mathrm{H}$. place $i$ and $H$. contortus. I haven't studied all of the other species. That is something we hope to do. I just don't know what will be a good identification character for the African species. The approach that we've used in the past is to try and find a marker character that can be used easily. Some of you may not think that cuticular ridges (synlophes) can be used easily, but with a little practice, I assure you they can. But I don't have a good answer for $H$. longistipes. That gives me the opportunity to make a point here; I think we need more systematists. They seem to be a dying breed. I know most of you know colleagues who work in this area and most have white hair like I do. I want to call your attention to the problem of moving parasites around the world with their hosts. Numerous species have been imported recently into the United States. Nematodirus battus of course goes back 10 or more years. Some of you in the audience have been involved recently in reporting Camelostrongylus, Longistrongylus, Spiculopteragia and Ostertagia leptospicularis. The latter was reported in North America first in cattle, but it was subsequently found in deer and it makes us wonder how long it has been here. This is a species that's normally parasitic in deer that does cause pathology in cattle. Eric Hoberg recently reported Echinococcus granulosis, the equine form, in a Maryland horse; the first report in the US Tridentoinfundibu- 
lum gobii is a species in horses that was reported in Louisiana; it's from Mongolia. Of course we know that horses are moved all over the world. I recently identified this species in Glasgow when I was there to look at parasites of horses. The last five species listed there are parasites of ratites which are now domestic animals. Eric Hoberg described a new species of Libyostrongylus and reported another that had been imported with ostriches and identified for the first time in North America. With the increased movement of domestic animals and the development of wild animal farms we're seeing a lot of parasites being moved around the world with their hosts.

(DeRosa - USA) With regard to Spiculopteragia, what is its taxonomic relationship to Mazamastrongylus? Has Mazamastrongylus (M. pursglovei, M. odocoilei) taken the place of Spiculopteragia or Teladorsagia within white tail deer? I thought there was some redescription of those.

(Lichtenfels - USA) They are all separate genera. The genus Mazamastrongylus is a good one with about eight species and Spiculopteragia is another; these are more related to each other than they are to the other Ostertagiinae.

(DeRosa - USA) But, have they been redescribed?

(Lichtenfels - USA) Several recent papers, including redescriptions of species of Mazamastrongylus, have been published. Eric Hoberg is working on Spiculopteragia.

(Hoberg - USA) They have fundamentally different geographic distributions. Spiculoteragia is a group found primarily in paleartic Cervids. Mazamastrongylus is primarily North American in Jansen's consideration of the group. Otherwise, there's a possibility that two species of Mazamastrongylus also occur in southeast Asia. But basically, all species of Spiculoteragia in North America at this time have been introduced from the paleartic, at least that's our consideration based on all the information available on host distribution.

(Lichtenfels - USA) In addition to the species of wildlife parasites that we know have been transferred to domestic food animals, other parasites of food animals are transferred to wild animals which then serve as reservoir hosts for domestic ruminants; for example, Haemonchus contortus and $H$. placei in white tail deer.

(Liu - USA) I just want to describe a little bit of work that we did recently related to molecular speciation, to sustain the theme that was raised by Ralph Lichtenfels and Dan Zarlenga primarily. I'm not a veterinary parasitologist, I'm actually a human parasitologist and was a consultant a little over a year ago with an enigmatic case of a human who came in with a dysentery-like syndrome. After an extensive workup the only thing that was found were numerous nematode larvae in the feces. We resorted to DNA methods to identify the larvae. One useful method 
employed PCR amplification of the D1 expansion segment of the large subunit ribosomal RNA that was in Dan's slide. Since this is a coding region, after amplifying a number of different species including representatives of all the major groups that infect humans, one would expect the same size D1 expansion segment. This is what we see on gels of the PCR products. These products were subsequently sequenced and we were able to do speciation on that basis. We have subsequently expanded this because it is quite a useful target for molecular taxonomy which has provided us some interesting insights into the phylogenetic relationships of the different major classes of zooparasitic nematodes and how they may be related to some other groups such as the free-living nematodes, in particular the model species $C$. elegans. There are some differences with traditional taxonomy. More relevant to the point of molecular specialization, we chose another target which is the intergenic spacer region between repeating $5 \mathrm{~S}$ ribosomal RNA genes. This is in a different gene locus than the 5.8S, $18 \mathrm{~S}$ and $28 \mathrm{~S}$ tandem repeats. It's in its own gene locus composed of 10 repeats and the thing that I illustrate here on the gel is that the size of the spacer is dramatically different between different major genera of intestinal nematodes. Shown here is DNA extracted from a single worm of our clinical case. The $5 \mathrm{~S}$ spacer from $C$. elegans is about 950bp; from Ancylostoma, which is a strongylid, less than 300bp; Ascaris, 1000bp; Enterobius, about 900bp; Strongyloides, somewhere around 250bp; Trichuris, about 750bp; and so forth. Just by looking at this gel we had a suspicion, in association with some preliminary morphological data, that our unknown species was in fact an oxyurid. Subsequent sequencing of these isolates confirmed this. The point is that in nematodes as different as these genera, this sort of one step diagnosis may suffice. It doesn't require subsequent cloning, or enzymatic manipulations, rapid analysis or restriction digestion to distinguish between different genera. We looked at this region of the genome in a few more widely disparate nematode species representing all the major traditional taxonomic groups. Again, I would show that the size of this molecular target varies greatly among the different classes. Some of you may also know that the ISLRNA that encodes the spliced leader sequence SL1, that is transpliced to the vast majority of pre-messenger RNAs of nematodes of the Class Secernentea, is also localized to the $5 \mathrm{~S}$ spacer in many groups. What was interesting is that we found it was consistently featured in the zooparasitic orders. That is, it was always on the plus strand relative to the $5 \mathrm{~S}$ coding region in ascarids and spirurids and always on the minus strand in the oxyurids. It was not present in the $5 \mathrm{~S}$ spacer at all in the strongylids. Again, we've only sampled a limited series and not very many nematode parasites of animals, but you can see the dramatic differences in the 5S spacer size within this sampling of the strongylids. We can take, for example, DNA from a single egg of hookworms (there are two species infecting humans) which at least to my eye are completely indistinguishable under the light microscope. But the length of the $5 \mathrm{~S}$ spacer from Ancylostoma and Necator varies and is different by more than 150 base pairs. So, we can distinguish, using single eggs which species is involved in a given case. In terms of the effort that's involved, these are relatively easy to amplify using fairly 
universal nematode primers and all of this work was really carried out by undergraduates in my lab, part-time, in less than a year.

(Lichtenfels - USA) In conclusion, l'd like to say that we've had some exciting progress in recent years in straightening out the situation with species pairs in the Ostertaginae in finding new characters that allow us to identify individual worms of both sexes and, with the exciting new techniques that are available with molecular genetics. I think we're on the threshold of making even more exciting advances in the future and I'd like to make the point that the best way for this progress to occur is to have a molecular biologist working with a morphologist. In the future we may have people that are trained in both techniques, but there are very few of those available right now. Those of you staffing laboratories should not forget the systematics component. If we don't support this area of research, it's going to disappear. So, I'd like to thank the organizers of this workshop for allowing systematics to be first on the program. There is nothing more important than knowing what species you're working with. If you know what species you're working with, thank a systematist. 